\title{
Technology spillovers and stability of international climate coalitions
}

\author{
Miyuki Nagashima $\cdot$ Rob Dellink
}

Accepted: 15 July 2008/Published online: 16 August 2008

(C) The Author(s) 2008. This article is published with open access at Springerlink.com

\begin{abstract}
Cooperation in international environmental agreements appears difficult to attain because of strong free-rider incentives. This paper explores how different technology spillover mechanisms among regions can influence the incentives to join and stabilise an international agreement. We use an applied modelling framework (STACO) that enables us to investigate the stability of partial climate coalitions. Several theories on the impact of technology spillovers are evaluated by simulating a range of alternative specifications. We find that spillovers are a good instrument to increase the abatement efforts of coalitions and reduce the associated costs. In our setting, however, they cannot overcome the strong free-rider incentives that are present in larger coalitions, i.e. technology spillovers do not substantially increase the success of international environmental agreements. This conclusion is robust with respect to the specification of technology spillovers.
\end{abstract}

Keywords Climate change modelling - International environmental agreements . Non-cooperative game theory $\cdot$ Technology spillovers

\section{Introduction}

Successful $\mathrm{CO}_{2}$ emission abatement requires international cooperation. However, full cooperation in the international environmental agreements (IEAs) seems to be difficult to achieve because of free-riding incentives. Game theoretic approaches are widely used to

M. Nagashima $(\bowtie) \cdot R$. Dellink

Social Sciences Group, Wageningen University, Hollandseweg 1, 6706 KN Wageningen,

The Netherlands

e-mail: miyuki.nagashima@wur.nl

M. Nagashima

Systems Analysis Group, Research Institute of Innovative Technology for the Earth, Kyoto, Japan

R. Dellink

Institute for Environmental Studies, VU University of Amsterdam, De Boelelaan 1085,

1081 HV Amsterdam, The Netherlands

e-mail: rob.dellink@ivm.vu.nl 
explore the properties of IEAs. For example, Barrett (1994) proves that stable coalitions will achieve little if the difference between the non-cooperative outcome and the fullcooperative outcome for each region is large. In order to solve this problem, numerous studies examine the effects of institutional settings aimed to stimulate voluntary participation in the IEAs, for example, through transfers (e.g. Carraro and Siniscalco 1993; Bloch 1997; Hoel and Schneider 1997; and Weikard et al. 2006). A general observation from this literature is that rather inefficient partial coalitions tend to emerge and the coalition with all the members may not be attained. De Zeeuw (2008) widens the scope to a dynamic context and confirms that large stable coalitions can only emerge when the gains from cooperation are small. Thus, even with transfers, full cooperation on emission abatement is hard to establish.

The purpose of this paper is to systematically investigate how various technology spillover mechanisms affect the formation and stability of climate coalitions in a noncooperative game. To do this, we use an integrated assessment model, STACO (Finus et al. 2006; Nagashima et al. 2006). We explore how technology spillovers that depend on the coalition that is formed influence the incentive structures to join the coalition. Moreover, we examine whether the effects of technology spillovers are large enough to stabilise more ambitious coalitions by offsetting the incentive to free-ride. We simulate several spillover mechanisms and specifications that are available in the literature to investigate the robustness of these links.

The paper is organised as follows. The remainder of this section sketches the main insights from the literature on technology cooperation and coalition formation. Section 2 provides the game theoretic and empirical framework of the STACO model, and introduces technology spillovers in the model. Section 3 reports the main results with technology spillovers, followed by an analysis of the impact of the level and direction of spillovers between coalition members and to outsiders in Sect. 4. Section 5 provides an analysis of alternative specifications of technology, and Sect. 6 concludes. The Appendix provides the model parameter values.

\subsection{Technology and coalition formation}

It has been commonly recognised that technological change plays a significant role in controlling climate change costs. In traditional neoclassical models, technological change is determined exogenously, where it increases factor productivity (e.g. for analytical studies, Arrow et al. 1961, Kennedy 1962 and Uzawa 1965, and for empirical studies, Peck and Teisberg 1994; Nordhaus 1994 and Nordhaus and Yang 1996). New growth theory places more emphasis on the endogenous role of technology and its positive externalities that drive economic growth (Romer 1990, Griliches 1992, and Grossman and Helpman 1994). Endogenous technological change can be measured in different ways (see Weyant and Olavson (1999) and Löschel (2002) for excellent surveys in the domain of climate change modelling). Löschel (2002) and Clark et al. (2008) present three main factors in endogenous technological change models: (1) research and development (R\&D) investment, (2) technology spillovers (between countries, industries or firms) and (3) learningby-doing.

In this paper, we focus on the role of technology spillovers between countries (cf. Coe and Helpman 1995) for the success of international climate agreements. As our framework is a cost-benefit analysis of climate policy, technology spillovers are not derived from $\mathrm{R} \& \mathrm{D}$ investment, but they are treated as factors that lead to cost reductions stemming from 
the level of knowledge in other regions. ${ }^{1}$ In short, technology spillovers depend on the 'state of technology' to reduce greenhouse gas emissions.

In the domain of coalition formation, a number of studies have proposed to link the agreements on emissions abatement with technological cooperation. The main idea of this mechanism is that each region negotiates not only on emission abatement but also negotiates on technological cooperation, which might induce regions to join a coalition. For example, Carraro and Siniscalco (1994), Cesar and De Zeeuw (1996) and Barrett (2003) indicate that linkage of the IEAs on climate control and technological cooperation may stabilise an IEA, as payoffs of signatories will increase due to increased technological spillovers from other signatories. Carraro and Siniscalco (1997) show that linkage of the environmental agreement with an agreement on technological cooperation may overcome free-riding problems due to the fact that the negotiation on both climate control and technology is more profitable to signatories when benefits from technological cooperation are exclusive to them than the negotiation on climate control only. Tol et al. $(2000,2001)$ investigate the diffusion of abatement technology and argue that when diffusion can be restricted to coalition members, this may reduce free-rider incentives, although countries prefer to cooperate only on technology and not on abatement. Kemfert (2004) shows in an applied coalition formation game with four regions that signatories can profit more when they cooperate on emission abatement and technological innovation than in the case of non-cooperation. Furthermore, there exist incentives for non-cooperating countries, such as U.S.A., to join an agreement in which countries cooperate both on emission abatement and technological innovations, because they can obtain technology spillovers, which improve energy efficiency through trade in goods with signatories; international trade effects are further investigated in Kemfert et al. (2004).

Buonanno et al. (2003) define the international spillovers of knowledge generated by a stock of world knowledge. In their setting, international knowledge spillovers affect both the production function and the emission to output ratio. Golombek and Hoel (2005) assume that the technology level of the region depends on own investments in R\&D and $R \& D$ investment in other countries (signatories) using a certain rate of technology diffusion, and R\&D activities in cooperating countries will lower abatement costs in noncooperating countries due to technology diffusion. Bosetti et al. (2007) have recently taken up this issue in an applied setting, using the multi-regional endogenous growth model WITCH.

Buchner and Carraro (2005a, b, 2006) explore the interactions between technology and coalition formation using the FEEM-RICE model. While their analysis touches upon the same topic as ours, they focus on a subset of possible coalitions and investigate stability issues only for those. This means that they cannot show the general implications of technology spillovers on coalition formation nor address which regions will participate in the most ambitious stable coalitions.

Most existing models assume that the level of environmental technology can be approximated by looking at the emission intensity of production, that knowledge can be aggregated over regions through summation and that spillovers have the effect of pivoting the marginal abatement cost (MAC) curve down. Recent literature suggests, however, that a 'best-shot' aggregation of technology may be more appropriate (Sandler 2006). Furthermore, alternative indicators of technology, based on for example energy intensity or carbon intensity, are also found in the applied literature (e.g. Kemfert 2004). Finally, Baker

\footnotetext{
${ }_{1}$ Growth theory considers spillovers as positive externalities, while innovation theory does not. For a detailed discussion, see Weyant and Olavson (1999).
} 
et al. (2008) and Bauman et al. (2008) challenge the conventional specification that spillovers (or learning, for that matter) pivot down the MAC curves. Baker et al. (2008) suggest two alternatives: an extension of the MAC curve to the right, and a change in the curvature of the MAC curve.

The general insight that emerges from these studies is that there are a number of different channels through which technology spillovers may affect the payoffs of regions and thus the incentives to cooperate: (i) global spillovers from a 'world stock of knowledge', (ii) spillovers that are directly derived from participation in the agreement (coalitional spillovers) and (iii) spillovers to outsiders. Furthermore, technology spillovers can be specified in different ways, depending on the answer to the essential questions of how to measure technology and how to specify the effects of spillovers on the MAC curve.

What all these studies lack, however, is a systematic analysis of the influence of technology spillovers on the stability of international climate agreements with heterogeneous players in an applied setting. Moreover, these studies do not shed light on the influence of the relative magnitude of spillovers between coalition members versus spillovers to outsiders, which can be a significant element for the success of climate coalitions.

\section{The stability of coalitions model (STACO)}

\subsection{Game theoretic background}

In this section, we describe the game theoretic model. Our analysis uses a two-stage, one shot game. In the first stage, regions denoted by $i \in N, N=\{1, \ldots, n\}$ decide whether they sign the agreement or not. Signatories form a coalition and non-signatories remain singletons in the second stage of the game. Then, all regions simultaneously determine their emission abatement levels. The payoff for each region $\pi_{i}$ is a function of regional benefits $B_{i t}$ and regional abatement costs $A C_{i t}$ at period $t$. Formally, we have:

$$
\pi_{i}(\mathbf{q})=\sum_{t=1}^{\infty}\left\{(1+r)^{-t} \cdot\left(B_{i t}\left(q_{1}, \ldots, q_{t}\right)-A C_{i t}\left(q_{i t}\right)\right)\right\}
$$

where $\mathbf{q}$ is an abatement matrix of dimension $N \times \infty$, and $r$ is the discount rate. The payoff is calculated as the net present value (NPV) of the stream of net benefits. We assume that the regional benefits depend on past and current global emission abatement, and the regional abatement costs depend on a region's own current abatement. The regional abatement levels are determined within the abatement strategy space $q_{i t} \in\left[0, \bar{e}_{i t}\right]$, where $\bar{e}_{i t}$ denotes emission levels in the business-as-usual (BAU) scenario.

We apply the solution concept of a partial agreement Nash equilibrium between the signatories and singletons (Chander and Tulkens 1995, 1997). We assume that signatories determine their abatement level by maximising the sum of the payoffs of the signatories taking the abatement levels of non-signatories as given. Non-signatories choose their abatement level by maximising their own payoffs taking the other regions' abatement levels as given. This abatement game has a unique interior solution under the STACO specification of benefit and cost functions (see Sect. 2.2).

We apply the optimal sharing rule developed by Carraro et al. (2006) and Weikard (2008). Optimal sharing requires that each signatory obtains at least the payoff that can be secured when it deviates from coalition $K$. This is called the outside option payoff. 
In addition, the residual is distributed in proportion to the outside option payoffs. ${ }^{2}$ Weikard (2008) shows that surplus sharing according to outside option payoffs internally stabilises all coalitions that are possibly stable under any sharing rule. That is, if the coalition payoff is distributed in such a way that each member gets at least its outside-option payoff, then no region has incentives to leave the coalition. Hence, the coalition is internally stable whenever the coalition payoff (weakly) exceeds the sum of the outside option payoffs.

We refer to the situations where none or one of the regions joins a coalition as 'All Singletons', and a coalition where all regions cooperate as 'Grand Coalition'. Following d'Aspremont et al. (1983), we call a coalition $K$ stable if the coalition satisfies both internal and external stability. Internal stability of a coalition means that no signatory has an incentive to withdraw from the coalition. External stability of a coalition means that no singleton has an incentive to join the coalition.

\subsection{The STACO model}

In this section, we present the main issues in the numerical specification of our model in a dynamic setting described in Nagashima et al. (2006), which is an extension of the original static STACO-1 model explained in Finus et al. (2006). We consider twelve world regions: USA (USA), Japan (JPN), European Union-15 (EU15), other OECD countries (OOE), Eastern European countries (EET), former Soviet Union (FSU), energy exporting countries (EEX), China (CHN), India (IND), dynamic Asian economies (DAE), Brazil (BRA) and rest of the world (ROW). Payoffs from abatement are given as the NPV of benefits minus abatement costs over the model horizon. We set the model horizon to infinity to capture future benefits from abatement, while adopting a planning horizon for abatement and coalition formation of 100 years, ranging from 2011 to 2110. Calibration of the regional BAU emission paths, ${ }^{3}$ represented in the Appendix (Fig. A1), is based on the data for $\mathrm{CO}_{2}$ emissions derived from the EPPA model (Babiker et al. 2001; J. M. Reilly 2005, pers. comm.) and the GDP path is also derived from the EPPA model. Our benefit function is based on a linearised approximation of avoided damages, calculated by using the damage module of the DICE model (Nordhaus 1994) and the climate module by Germain and van Steenberghe (2003). For global damages, we apply the estimate by Tol (1997) that damages amount to $2.7 \%$ of GDP for a doubling of concentrations over pre-industrial levels. Global benefits are allocated according to a fixed share for each region, as displayed in Appendix (Table A2). We specify a regional abatement cost function based on the estimates of the EPPA model by Ellerman and Decaux (1998).

\subsection{Technology spillovers}

In our base model, we adopt the (common) assumption that technology spills over to region $i$ in period $t\left(\varsigma_{i t}\right)$ by reducing marginal abatement costs through pivoting of the MAC curve ${ }^{4}$ :

$$
\mathrm{MAC}_{i, t+1}=\left(1-\varsigma_{i, t}\right) \cdot \mathrm{MAC}_{i, t}
$$

Or equivalently,

\footnotetext{
2 The residual can be shared by each coalition member in any way desired, because it does not affect internal stability as long as these shares are non-negative.

3 We use data from World Bank (2003) to match the regional aggregation in EPPA to STACO.

4 We investigate alternative assumptions in Sect. 5.
} 


$$
\mathrm{MAC}_{i, t} \equiv \frac{\partial A C_{i t}}{\partial q_{i t}}=\alpha_{i} \cdot\left(\prod_{s=2011}^{t-1}\left(1-\varsigma_{i s}\right)\right) \cdot q_{i t}^{2}+\beta_{i} \cdot\left(\prod_{s=2011}^{t-1}\left(1-\varsigma_{i s}\right)\right) \cdot q_{i t},
$$

where $\prod_{s=2011}^{t-1}\left(1-\varsigma_{i s}\right)$ reflects the product of technological spillovers until period $t$, and $\alpha$ and $\beta$ are the abatement cost parameters in our base year 2010.

The size of the technology spillover depends on which regions are member of the coalition. We assume that the spillovers will be higher when more regions are member of the coalition, and when regions with an advanced state of technology are member of the coalition, but the size of the spillover cannot be controlled by the coalition members, as their state of technology is exogenous. Spillovers to region $j$ in period $t\left(\varsigma_{j t}\right)$ are expressed through a summation over all players of the regional spillover effect times the state of technology:

$$
\varsigma_{j t}=\sum_{i=1}^{N} \xi_{i j} \cdot \operatorname{SoT}_{i t}
$$

with $0 \leq \xi_{i j}<1$ the spillover effect from region $i$ to region $j$. In different scenarios, the value of $\xi_{i j}$ varies, depending on whether $i$ and/or $j$ are member of the coalition. Unfortunately, there is no strong empirical base to calibrate the values of $\xi_{i j}$. Therefore, we conduct a robustness analysis by changing the values of these spillover coefficients in Sect. 4.

The 'state of technology' (SoT) used in Eq. 4 is the inverse of the regional emission intensity in the reference path, calculated as the business-as-usual amount of $\mathrm{CO}_{2}$ emission per unit of GDP. ${ }^{5}$ The rationale for this definition is that regions that have low emission intensities have a high level of knowledge on GHG abatement strategies. To investigate the robustness of this definition, we compare some alternative definitions in Sect. 5. As we use the state of technology as an indicator of the level of knowledge, we refer to the emission intensity in the reference path and do not adjust for changes in the emission intensity due to abatement. This is because we interpret abatement primarily as a movement along the technology curve, i.e. adoption of existing knowledge, rather than a shift of the curve, i.e. creation of new knowledge. As for the state of technology, Table 1 shows that Japan has the highest state of technology throughout the century, followed by EU15. On the other hand, U.S.A. and China have relatively low states of technology.

To investigate the role of spillovers on coalitional stability in a systematic manner, we investigate five scenarios, which differ with respect to the type of spillover between regions.

In the first or reference scenario, we consider coalition formation in the absence of technology spillovers, and do not assume any technological progress. We assume no technology spillovers among regions: $\xi_{i j}=0$.

In the second scenario, we assume regional spillovers that depend only on the own state of technology, i.e. internal spillovers. Therefore, we have $\xi_{i i}=\overline{\xi^{\text {own }}}>0, \xi_{i j}=0 \forall j \neq i$. Although we have no solid empirical basis for the size of this internal spillover, we assume $\overline{\xi^{\text {own }}}=0.01$. As the regional state of technology will always be smaller than unity, this implies technology spillovers of less than $1 \%$ per annum.

In the third scenario, we assume global spillovers, which mimics international spillovers of knowledge generated by 'the stock of world knowledge' as in Buonanno et al. (2003), although our model is much simpler and thus cannot capture the knowledge creation aspect. We rather focus on the link between technology spillovers and incentives to cooperate in an IEA. In this context, the essence of the global spillovers is that every region

\footnotetext{
5 We scale the SoTs such that global SoT equals 1 in 2110.
} 
Table 1 State of technology based on emission intensity

\begin{tabular}{ccccccccccccc}
\hline Year & USA & JPN & EU15 & OOE & EET & FSU & EEX & CHN & IND & DAE & BRA & ROW \\
\hline 2011 & 0.02 & 0.06 & 0.04 & 0.02 & 0.01 & 0.00 & 0.01 & 0.01 & 0.01 & 0.02 & 0.03 & 0.02 \\
2060 & 0.05 & 0.12 & 0.08 & 0.04 & 0.01 & 0.01 & 0.03 & 0.02 & 0.02 & 0.05 & 0.07 & 0.04 \\
2110 & 0.07 & 0.21 & 0.14 & 0.06 & 0.03 & 0.02 & 0.06 & 0.04 & 0.03 & 0.11 & 0.16 & 0.08 \\
\hline
\end{tabular}

Note: The state of technology is based on the inverse of BAU emissions over GDP for each region (ton/ US1000\$) and we scale the state of technology such that the global state of technology equals 1 in 2110

obtains technology spillovers, irrespective of membership of the coalition or not: $\xi_{i j}=$ $\xi^{\text {global }}>0$. We assume that this global spillover replaces the internal spillover from scenario $2\left(\overline{\xi^{\text {own }}}=0\right)$. Assuming the same spillover rate, that is, $\overline{\xi^{\text {global }}}=0.01$, leads to technological progress slowly increasing over the century to $1 \%$ per annum.

In the fourth scenario, in addition to the global spillovers, signatories to the climate agreement gain spillovers from the other coalition members (cf. the 'coalition information exchange parameter' in Carraro and Siniscalco 1997); this scenario also refers to the mechanism in Kemfert (2004) that participants cooperate on technological innovation. With coalitional spillovers, in addition to global spillovers, signatories can obtain higher spillovers from other signatories, that is,

$$
\left\{\begin{array}{l}
\xi_{i j}=\overline{\xi^{C}}+\overline{\xi^{\text {global }}}>0 \quad \forall i, j \in K \\
\xi_{i j}=\overline{\xi^{\text {global }}}>0 \quad \text { else. }
\end{array}\right.
$$

We calibrate coalitional spillovers to $\overline{\xi^{C}}=0.005$ and still $\overline{\xi^{\text {global }}}=0.01$.

This scenario is expected to provide a stimulus for regions to join a coalition, as membership brings technology benefits, although the effect is assumed to be moderate, as it is on top of the global spillover effect.

In the fifth scenario, following Golombek and Hoel (2005), we consider all possible technology spillovers, i.e. we extend the mechanism of the third scenario with spillovers to singletons (which we label 'extended spillovers'). In this setting, not only signatories benefit from internal coalition spillovers, but also singletons can obtain spillovers from signatories, that is

$$
\left\{\begin{array}{l}
\xi_{i j}=\overline{\xi^{C}}+\overline{\xi^{\text {global }}}>0 \quad \forall i, j \in K \\
\xi_{i j}=\overline{\xi^{N C}}+\overline{\xi^{\text {global }}}>0 \quad \forall i \in K ; \forall j \notin K \\
\xi_{i j}=\overline{\xi^{\text {global }}}>0 \quad \text { else },
\end{array}\right.
$$

where extended spillovers $\left(\overline{\xi^{N C}}\right)$ equal 0.001 and still $\overline{\xi^{C}}=0.005$ and $\overline{\xi^{\text {global }}}=0.01$. In this case, we assume that a region can also benefit from its own contribution to the coalitional spillovers not as in the case of internal coalitional spillovers, and that outsiders can get some ratio of spillovers from the coalition. Following Carraro and Siniscalco (1997), we assume that the diffusion rate among coalitions is larger than the one towards outsiders.

\section{Results}

As we cannot properly estimate the values of different $\xi$, our analysis of the results focuses on the impact of varying levels of spillovers on stability of climate coalitions (Sect. 4), and 
a comparison of different specifications (Sect. 5). Nonetheless, it is instructive to start with an analysis of the stability for all 4,084 coalition structures for the five scenarios.

In order to improve comparison of the results across scenarios, we need normalisation as larger technology spillovers imply larger NPV of payoffs (through lower abatement costs). We calculate the percentage of the gap between Grand Coalition and All Singletons that is closed by a coalition, which can be interpreted as a normalised indicator of success of the coalition. ${ }^{6}$ Table 2 shows the best-performing stable coalitions in all scenarios of technology spillovers, the associated NPV of global payoffs in billion dollars and the associated indicator of success. We obtain 185 stable coalitions in the cases of no spillovers and internal spillovers, and 182 stable coalitions in the case of global spillovers. Clearly, global spillovers lead to higher absolute payoffs than no spillovers and internal spillovers for any given coalition structure. While marginal abatement costs are lower and payoffs are higher in the presence of technology spillovers, the incentives to join or leave a coalition are not significantly influenced. The best performing coalition, in terms of global payoff and indicator of success, is formed by the USA, EET, CHN, IND and DAE. While absolute payoffs increase with global spillovers, the indicator of success remains virtually unchanged: the spillovers affect all coalitions and also the gap between Grand Coalition and All Singletons. As the incentives to change membership depend on a comparison of different coalitions, the absolute values are much less important than the relative differences. The indicator of success shows that these relative differences hardly change, which implies that the incentives to change membership hardly change. A first conclusion can therefore be that internal and global technology spillovers are not successful instruments to enhance the stability of climate coalitions.

Under coalitional spillovers, where coalition members benefit from partners through technology spillovers, we have 193 stable coalitions. There are two mechanisms at work here. First, the indicator of success for any given coalition is lower than in the case of no, internal and global spillovers (although absolute payoffs are higher). This is due to the fact that the rate of technology spillovers depends on the coalition formation and these spillovers work best in the Grand Coalition, i.e. they increase the gap between the Grand Coalition and All Singletons. Second, new coalitions stabilise that are more ambitious, in this case, the coalition of USA, EET, EEX, CHN and IND. That these two mechanisms counteract each other is confirmed by the small decrease in the average indicator of success.

In the case of extended spillovers, global payoffs and the associated indicator of success are slightly higher than in the case of coalitional spillovers. The reason is that the spillovers to outsiders are not reflected in the Grand Coalition; therefore, the gap between the NPV of global payoffs in Grand Coalition and in All Singletons is the same for coalitional spillovers and extended spillovers, while the NPV of global payoffs for any given coalition is larger in the case of extended spillovers as singletons can benefit from the spillovers generated by the coalition members. In our setting, however, the extended spillovers are not sufficiently strong to substantially alter the set of stable coalitions. We will investigate this finding in more detail in Sect. 4.

In the coalitional and extended spillover scenarios, the number of stable coalition increases and new stable coalition between USA, EET, EEX, CHN and IND emerges, which ranks first. That the stable coalition consisting of six regions between USA, EET, EEX, CHN, DAE and BRA does not rank in the top five shows that the size of the coalition does not necessarily dictate the ambition level of the coalition: in the setting with heterogeneous regions, a small coalition of 'key players' may be more successful than a large coalition.

\footnotetext{
${ }^{6}$ The indicator of success for a coalition is calculated as the difference between the NPV of global payoff when a coalition is formed and in All Singletons divided by the difference between the NPV of global payoff in the Grand Coalition and in All Singletons.
} 


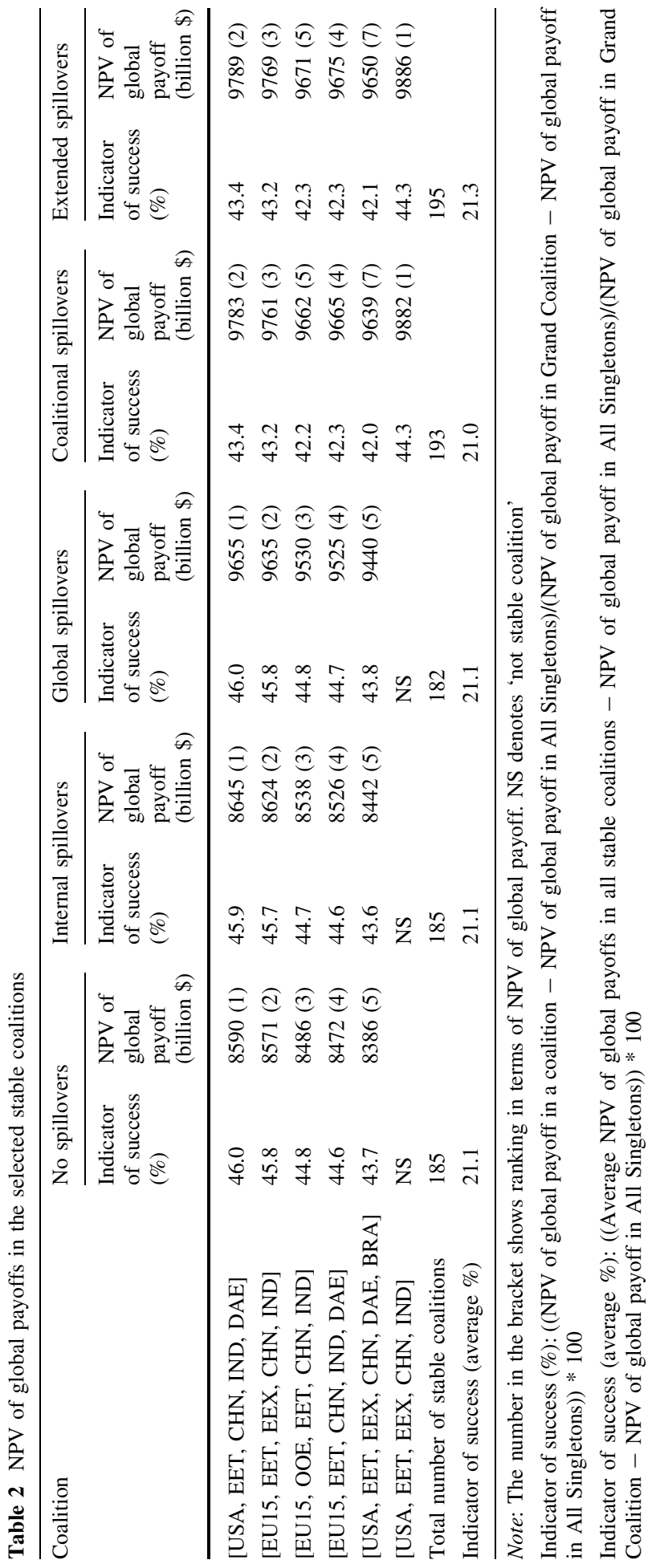


For these five scenarios, we can conclude that only moderately small stable coalitions emerge, which close the gap between the Grand Coalition and All Singletons by less than $50 \%$. Furthermore, while coalitional spillovers do increase payoffs and stabilise somewhat more ambitious coalitions, they also increase the gap between Grand Coalition and All Singletons, making the indicator of success smaller.

In the fourth and fifth scenarios, the coalition is assumed to be able to control the technology spillovers, albeit only partially in the extended spillover case. This setting can be interpreted as a model in which the public good (abatement) is coupled with a club good (technological knowledge; for details on club goods, see Sandler and Tschirhart 1997). The provision of the public good is affected by the presence of the club good. In our setting, the coalition may be able to control which regions share in the club good, but it does not deliberately choose the level of provision of the club good: it is not an independent choice variable. This is due to our assumption that spillovers are linked to the exogenous state of technology of the coalition members. Thus, the public good game does not affect the provision of the club good for any given coalition. Still, the model does of course capture the effect that when more regions join the coalition, both the level of abatement (the public good) and the level of technology spillovers (the club good) increase.

\section{Disentangling the impact of coalitional spillovers}

As shown in the previous section, coalition spillovers can enhance stability to some extent, although the indicator of success is lower than in the other scenarios. To understand the main elements that stabilise the coalition, we address the following questions: Does the magnitude of the technology spillovers created by the coalition (the 'level effect') matter? Does the relative rate of the coalitional spillovers between the coalition members and outsiders (the 'asymmetry effect') influence the success of climate coalitions? In order to explore the main driving forces, we explore these two questions by varying the level of coalitional and extended spillovers in Sect. 4.1 and by varying the ratio between coalitional and extended spillovers in Sect. 4.2. We consider the case of extended spillovers examined in Sect. 3 as the 'base case' in the following sections.

\subsection{Analysis of the impact of the level effect}

In the first analysis, we explore the level effect on the stability of coalitions by increasing the magnitude of the coefficient of coalitional and extended technology spillovers. We examine the stability of all coalitions using different values of coalitional spillovers to coalitional members $\left(\overline{\xi^{C}}\right)$ and to outsiders $\left(\overline{\xi^{N C}}\right)$, moving from 0.005 to 0.05 for coalition members and from 0.001 to 0.01 for outsiders in five steps, while the ratio of the coalitional spillovers to coalitional members over spillovers to outsiders remains the same.

The results of these calculations are summarised in Table 3, which shows the NPV of global payoffs and associated indicator of success for the best-performing stable coalitions. The results show that the best-performing stable coalitions substantially change with the magnitude of spillovers. It is likely that Brazil and Japan, who have higher marginal abatement costs, have incentives to join the coalition as spillovers increase. For example, the coalition of EU15, EET, CHN, IND and DAE, which ranks fourth in the base case model, is not stable anymore as spillovers increase, whereas these regions complemented by Brazil form a new stable coalition. In line with the analysis in Sect. 3, the indicator of 


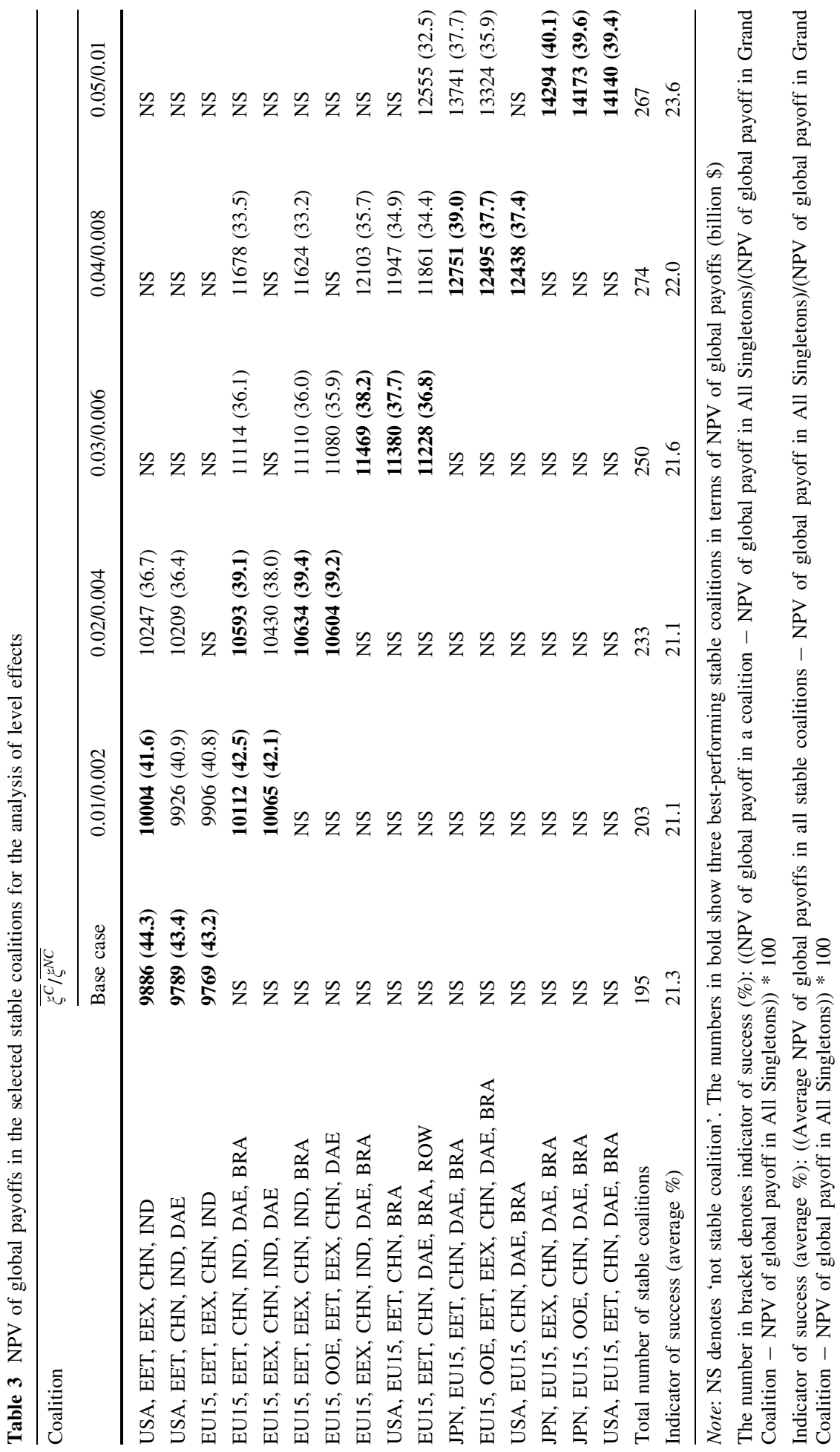


success for each stable coalition decreases with higher spillovers, as is clearly shown in Table 3. Higher spillovers imply higher global payoffs in the Grand Coalition, while the global payoff in the All Singletons remains the same across all spillover levels. This difference is so large that the indicator of success decreases substantially with increasing spillovers for a given stable coalition. The conclusion can be drawn that larger spillovers tend to increase the size of stable coalition (up to seven members), and largely change the structure of the stable coalitions, but the level effect may not have large effects on the indicator of success.

\subsection{Analysis of the impact of the asymmetry effect}

In the second analysis, we focus on the effects of the relative rate of the coalitional spillovers between the coalition members in comparison to spillovers to outsiders on the stability of coalitions. We explore this asymmetry effect in two ways. First, we increase the coefficient of coalitional spillovers to outsiders in four steps while keeping those to coalition members the same as in the base case. Second, we increase the coefficient of coalitional spillovers to coalition members while those to outsiders remain the same. We suspect that larger asymmetry between technology spillovers among signatories versus outsiders may enhance larger stable coalitions. The larger spillovers induce signatories to stay in the coalition, and thus additional internally stable coalitions are expected to emerge. The large coalitional spillovers attract potential new entrants because coalition members can get higher benefits from increased abatement by reducing emissions at lower costs than in the base model.

Table $4 \mathrm{a}$ shows the results of the asymmetry effects when the coefficient of coalitional spillovers to outsiders increases. The results suggest that the four best-performing stable coalitions remain the same, regardless of the level of extended spillovers. Thus, while the numbers change slightly, the table clearly shows that the asymmetry effect is of little importance for the stability of climate coalitions. ${ }^{7}$

Table $4 \mathrm{~b}$ presents the results of the asymmetry effect when the coalitional spillovers increase, keeping the extended spillovers constant (thereby making the wedge between both larger). The table largely combines the insights from Tables 3 and $4 \mathrm{a}$ : the level effect dominates the asymmetry effect, and thus, Table $4 \mathrm{~b}$ looks very similar to Table 3 . While the level effect does stabilise larger (although not necessarily more ambitious) coalitions, as it increases the gap between Grand Coalition and All Singletons, the indicator of success does not increase with increasing spillovers. Again, we can draw the conclusion that the asymmetry effect is of minor importance. The main explanation for the limited importance of the asymmetry effect is that for the stability of climate coalitions, internal stability (i.e. no coalition member wants to leave the coalition) is a much more important condition than external stability (i.e. no outsider wants to join the coalition): increasing coalitional spillovers can be associated with increasing the internal stability (to some extent at the expense of weakening external stability), as they increase the surplus generated by the coalition. Spillovers to outsiders have a more complicated impact, as they increase the incentives to free-ride (and thus increase external stability and reduce internal stability), but they also imply higher global abatement levels and thus increase payoffs for coalition members as well. Furthermore, if an outsider decides to join the coalition, its membership will increase the technology spillovers created by the enlarged coalition, again leading to higher benefits for the region itself and for other regions. Consequently, these effects

7 This conclusion may not hold for much larger values of the extended spillovers, but we feel that much higher values would not be realistic. 


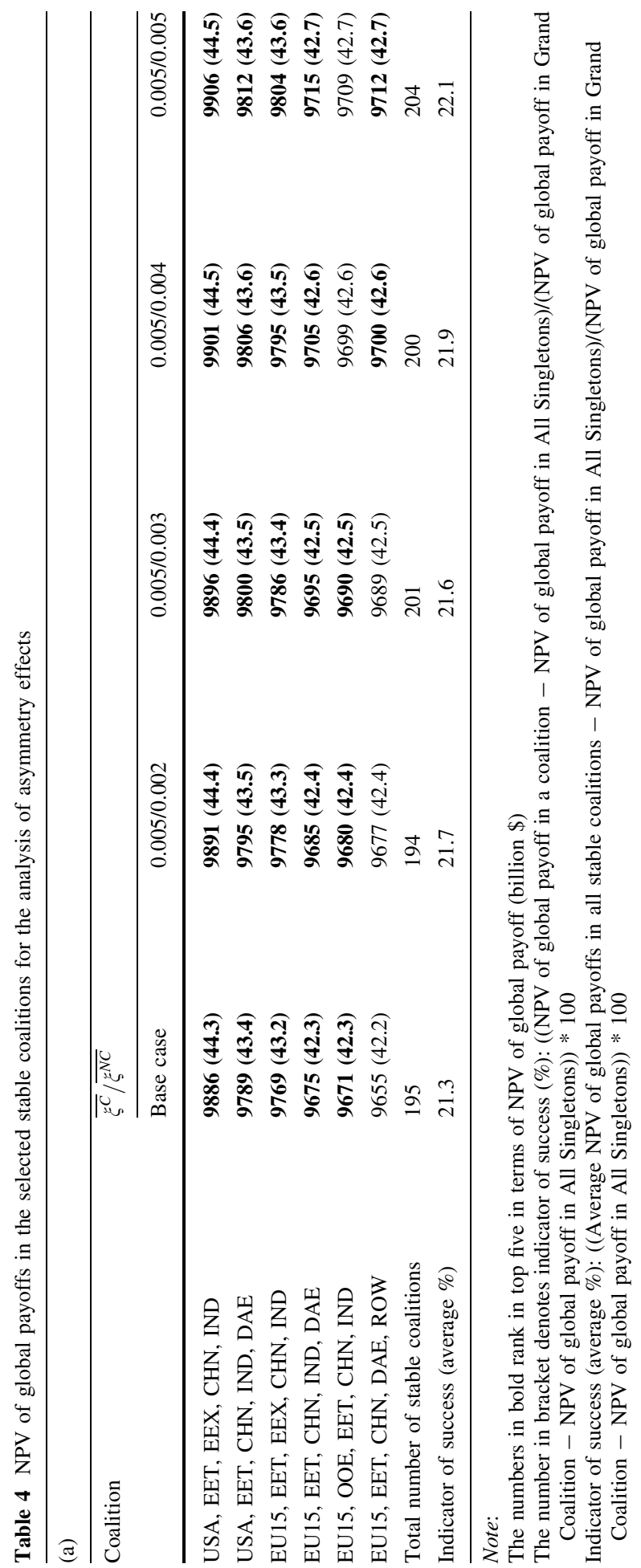




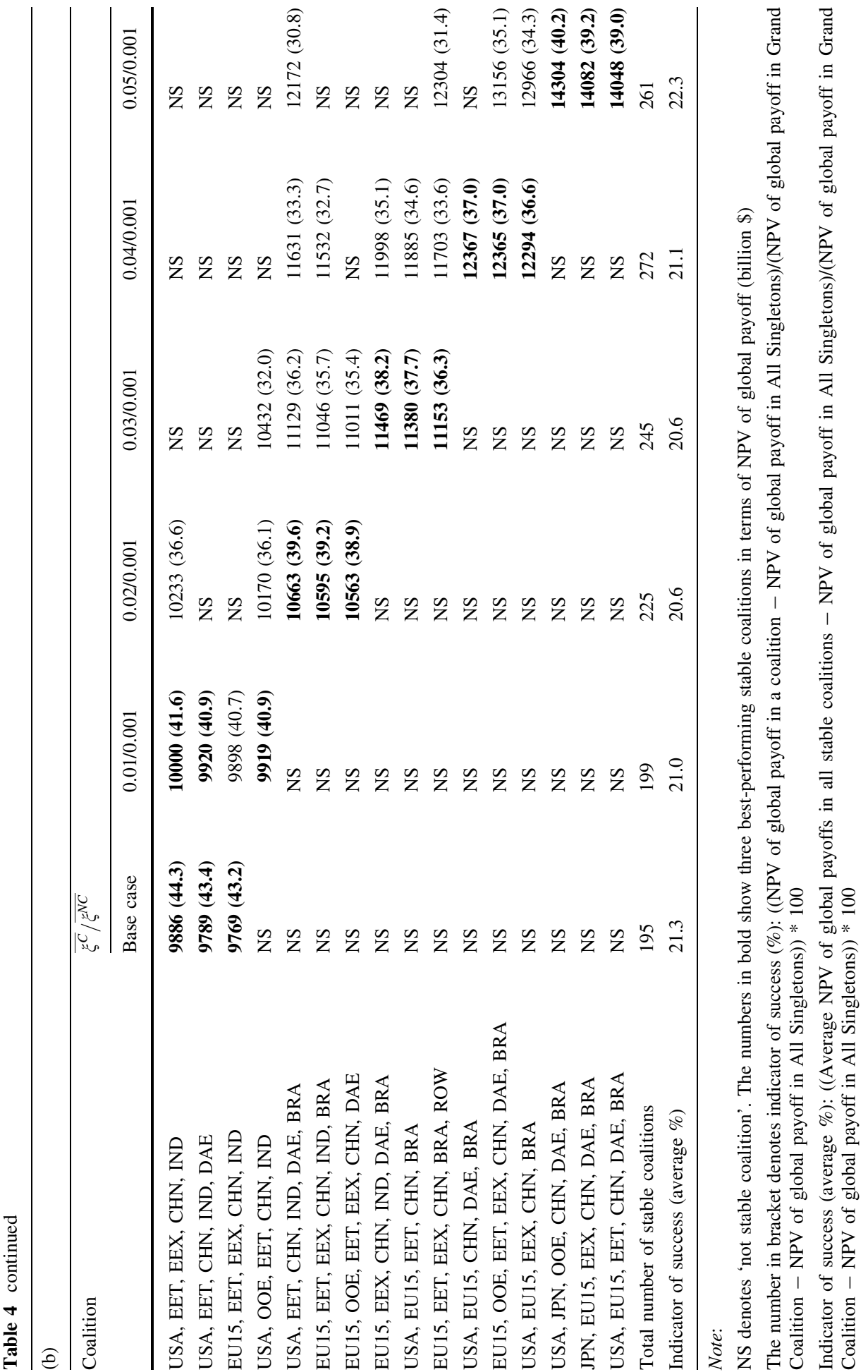


mitigate each other and the result emerges that increasing spillovers to outsiders does increase abatement levels and payoffs but does not stabilise larger coalitions.

\section{Alternative specifications and sensitivity analysis}

In order to investigate the robustness of our results, we simulate various alternative specifications of technology spillovers by (i) varying the aggregation of technology, (ii) using different indicators for the state of technology and (iii) changing the impact of spillovers on the MAC curve. In addition, as we believe that a crucial parameter in the model is the discount rate $r$, this is subjected to a sensitivity analysis. For ease of comparison, we use the base model with extended spillovers as the reference case. Table 5a presents the results of the alternative specifications and the sensitivity analysis on the discount rate; these results will be discussed in the next sections.

\subsection{Alternative aggregation of technology}

In the simulations above, the assumption is that knowledge ('state of technology' in our terminology) can be summed over regions to identify the size of the spillovers. According to Sandler (2006), however, 'Knowledge is the quintessential best-shot or better shot public good, where breakthroughs come from concentrating effort and building up research centers of excellence'. Therefore, we can construct an alternative spillover formulation where we follow Sandler's definition and define spillovers through a best-shot aggregation of technology. The implication of the best-shot aggregation (Hirshleifer 1983; Sandler 2006) is that the technology spillovers depend on the maximum state of technology in a coalition, rather than the sum of technologies. In the field of GHG abatement technologies, the rationale for the best-shot aggregation is that the technologies that regions have to reduce emissions will have substantial (or even full) overlap with the technologies in other regions. Consequently, the region with the highest state of technology will not learn from others. In this section, we explore the effects of best-shot aggregation on the stability of coalitions under the internal and extended coalitional spillovers. To reflect a region's capability of adopting advanced technology, we modify the spillover specification in Eq. 4 such that the spillover depends on the difference between the highest state of technology and the region's own state of technology. Hence, the spillovers ${ }^{8}$ can be defined as follows:

$$
\left\{\begin{array}{l}
\varsigma_{i t}=\overline{\xi^{C}} \cdot\left\{\max _{j \in K}\left(\operatorname{SoT}_{j, t}\right)-\mathrm{SoT}_{i, t}\right\}+\overline{\xi^{\mathrm{global}}} \cdot\left\{\max _{j \in N}\left(\mathrm{SoT}_{j, t}\right)-\mathrm{SoT}_{i, t}\right\} \forall i \in K ; \\
\varsigma_{i t}=\overline{\xi^{N C}} \cdot\left\{\max _{j \in K}\left(\mathrm{SoT}_{j, t}\right)-\mathrm{SoT}_{i, t}\right\}+\overline{\xi^{\mathrm{global}}} \cdot\left\{\max _{j \in N}\left(\mathrm{SoT}_{j, t}\right)-\mathrm{SoT}_{i, t}\right\} \forall i \notin K .
\end{array}\right.
$$

The 'Best-shot' column in Table 5a shows the NPV of global payoffs for the bestperforming stable coalitions with the best-shot technology aggregation (assuming extended coalitional spillovers). We can observe that the five best-performing stable coalitions remain the same but the indicators of success for these coalitions are slightly higher than in the base model, which can be explained by the fact that the level of spillovers is somewhat smaller than in our base case. The results suggest that the aggregation method does not change the qualitative outcomes of the analysis.

\footnotetext{
8 All spillover coefficients are unchanged, and in the best-shot aggregation, we rescale the SoTs such that the maximum SoT equals 1 in 2110.
} 


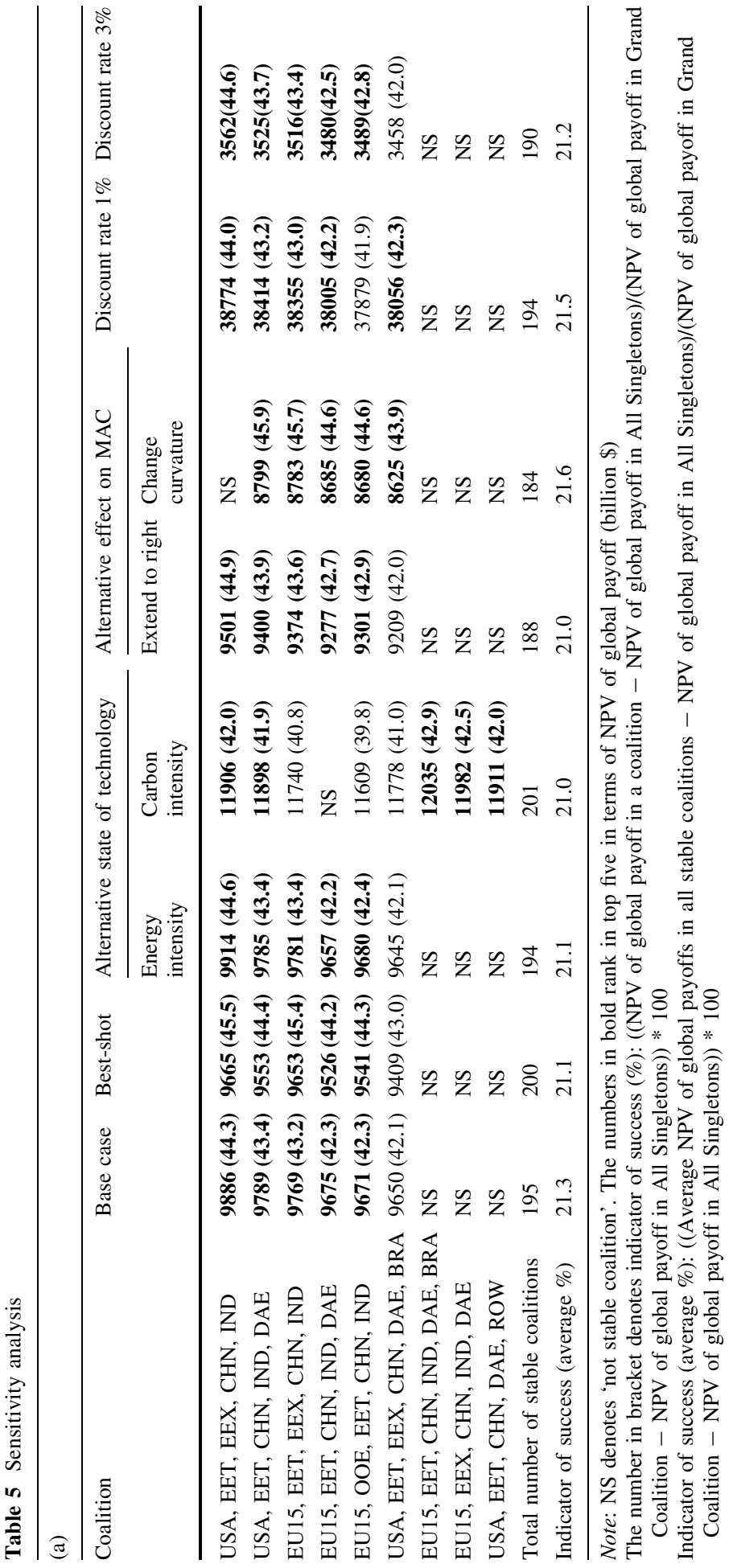




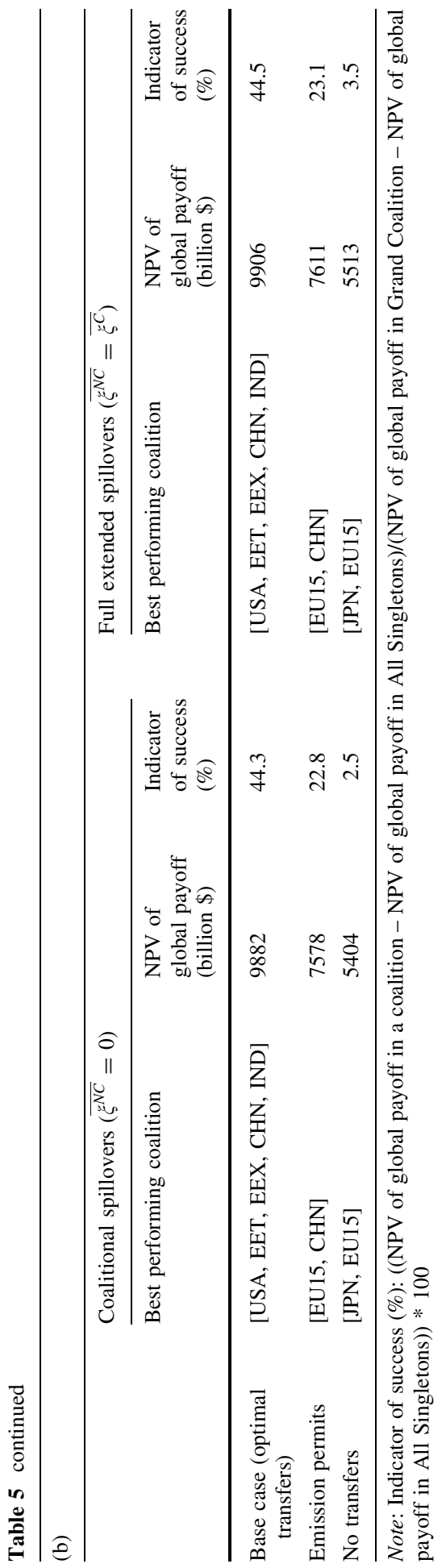




\subsection{Alternative indicators for state of technology}

In this section, we consider alternative indicators for state of technology, using energy intensity or carbon intensity instead of emission intensity. Energy intensity is calculated as energy use ${ }^{9}$ per unit of GDP, whereas carbon intensity is calculated as the amount of $\mathrm{CO}_{2}$ emitted per unit of energy. Emission intensity is used among others by Carraro and Siniscalco (1997), while Kemfert (2004) uses energy intensity. The fourth and fifth columns in Table 5a show the best-performing stable coalitions with these alternative indicators of state of technology. With the state of technology based on energy intensity, we obtain the same five best-performing stable coalitions as in the base case. This is because the regional trends of energy intensity are similar to the trends of the emissions-output ratio. In contrast, with the state of technology based on carbon intensity, most of the stable coalitions are the same but additionally other stable coalitions emerge. In our model, emission and energy intensities decrease over time, but this is not the case with carbon intensity. This shows that while emission intensity and energy intensity are more or less interchangeable as an indicator of the state of technology in addressing climate change, carbon intensity is a very different indicator, which leads to different stable coalitions.

\subsection{Alternative levels of spillovers on the MAC curve}

The effect of technology spillovers (and learning) on the shape of the marginal abatement cost (MAC) curve is hardly ever subjected to a thorough analysis, even though suspicion of the effect of technical change on marginal abatement costs was already put forward more than 20 years ago by Downing and White (1986). Recently, two papers emerged, Baker et al. (2008) and Bauman et al. (2008), which challenge the conventional assumption that technological change will pivot the MAC curve down. Bauman et al. (2008) take up the argumentation of Downing and White (1986) and show that in certain circumstances, technological change may even increase marginal abatement costs. Baker et al. (2008) review the literature and derive that different technology options will have a different impact on marginal abatement costs. Following Baker et al. (2008), we adopt two alternatives to our base model: (i) technology spillovers will extend the MAC curve to the right, and (ii) technology spillovers will affect the curvature of the MAC curve.

In model terms, this implies that we separate the effects of the spillovers on the two parts of our MAC function (Eq. 3 in Sect. 2.3). In the base case, a spillover will reduce both parameters $\alpha$ and $\beta$. We approximate an extension of the curve to the right as a spillover effect that will only affect parameter $\alpha$ (to the same extent as in the base model), leaving parameter $\beta$ unchanged. This implies that the initial slope of the MAC curve is unchanged, but the curvature is reduced. In the alternative with a changed curvature, we assume that technology spillovers will reduce the initial slope of the MAC curve, but increase the curvature (where we assume the effect is smaller but not insignificant). In mathematical notation, we have:

Base model:

$$
\operatorname{MAC}_{i, t} \equiv \frac{\partial A C_{i t}}{\partial q_{i t}}=\alpha_{i} \cdot\left(\prod_{s=2011}^{t-1}\left(1-\varsigma_{i s}\right)\right) \cdot q_{i t}^{2}+\beta_{i} \cdot\left(\prod_{s=2011}^{t-1}\left(1-\varsigma_{i s}\right)\right) \cdot q_{i t}
$$

\footnotetext{
9 The trajectory of final energy is based on the EPPA model (J. M. Reilly 2005, pers. comm.).
} 


$$
\text { Extension: } \quad \mathrm{MAC}_{i, t} \equiv \frac{\partial A C_{i t}}{\partial q_{i t}}=\alpha_{i} \cdot\left(\prod_{s=2011}^{t-1}\left(1-\varsigma_{i s}\right)\right) \cdot q_{i t}^{2}+\beta_{i} \cdot q_{i t}
$$

Change curvature:

$$
\operatorname{MAC}_{i, t} \equiv \frac{\partial A C_{i t}}{\partial q_{i t}}=\alpha_{i} \cdot\left(\prod_{s=2011}^{t-1}\left(1+0.1 \cdot \varsigma_{i s}\right)\right) \cdot q_{i t}^{2}+\beta_{i} \cdot\left(\prod_{s=2011}^{t-1}\left(1-\varsigma_{i s}\right)\right) \cdot q_{i t}
$$

where $\Pi$ denotes the product over time.

The main results of these alternative specifications can be found in the sixth and seventh columns of Table 5a. In the alternative specifications, the total spillover effect is somewhat smaller than that in the base model (as the effect on $\beta$ is missing, and the effect on $\alpha$ is reversed, respectively), and as expected, the indicator of success for each coalition is generally larger and the payoff smaller than in the base model. In the first alternative, the ranking of the bestperforming stable coalitions is unaffected. In the second alternative, the level of spillovers is substantially smaller (as can be seen from the lower payoffs for a given coalition), and consequently, the coalition that ranks first in the base model is not stable, but there are not many other changes in the stability of coalitions. Thus, we conclude that while the impact of the shape of the MAC curve cannot be ignored, the qualitative conclusions still hold.

\subsection{Changing discount rate}

We change the base value of the discount rate $r$ from $2 \%$ to $3 \%$ and $1 \%$, respectively, reflecting a higher (lower) rate of time preference. As shown in the eighth and ninth columns of Table 5a, increasing (decreasing) the value of $r$ will decrease (increase) the NPV of global payoffs as future benefits from abatement are valued lower (higher), but the set of bestperforming stable coalitions and the indicator of success for these coalitions remains largely the same as the base case: the relative comparison between different coalitions, which is what matters for stability analysis, is not substantially affected by the discount rate.

\subsection{Alternative transfer schemes}

The purpose of this section is to explore to what extent our finding of very limited asymmetry effects is influenced by the adopted type of transfer scheme, by comparing coalitional spillovers (i.e. no spillovers to outsiders) with full spillovers to outsiders (i.e. equal to spillovers to coalition members. Table $5 \mathrm{~b}$ shows that the best-performing stable coalitions vary with the type of transfer scheme (conform to the expectations and earlier results for a setting without spillovers reported in Nagashima et al. 2006). The results also show that the asymmetry effect does not matter for which coalition emerges as bestperforming, given the transfer schemes. There is a tendency that less efficient transfer schemes imply a larger positive effect of spillovers to outsiders, but this is because less efficient transfer schemes imply smaller and less ambitious stable coalitions, and thus a larger number of outsiders. Thus, we can conclude that the conclusion on the limited asymmetry effect is not directly related to the choice of transfer scheme.

\section{Discussions and conclusions}

In this paper, we explore the effects of technology spillovers among heterogeneous regions on the stability of possible climate coalitions with optimal transfer scheme. We identify 
technology spillovers through three major channels, and investigate how technology spillovers can influence the region's incentive structure to join the coalition. It should be noted that we leave the issues of a separate technology agreement and endogenous learning effects for further analysis; thus, the spillovers we investigate are exogenous. For future research, it will also be worthwhile to examine endogenous feedback effects from abatement on the state of technology and the impacts on the stability of climate coalitions.

Our main finding is that while global and coalitional spillovers can generate higher payoffs and boost global abatement levels, technology spillovers do not substantially increase the success of international climate agreements.

By and large, technology spillovers exclusive to coalitional members do increase their incentive to stay in the coalition and their efforts to reduce emissions, which leads to increased stability. However, as the gap between full cooperation (the Grand Coalition) and no cooperation (All Singletons) also increases with the size of coalitional spillovers, the relative success of a coalition, measured in terms of the percentage of the gap between Grand Coalition and All Singletons that is closed by the coalition, mostly decreases with the level of coalitional spillovers.

Furthermore, spillovers to outsiders have a mixed influence on the incentives to freeride, and thus the set of stable coalitions remains largely unchanged. This also leads to the surprising finding that the ratio (asymmetry) between spillovers to coalition members and to outsiders is hardly important for the stability of coalitions. Thus, the analysis in this paper shows that spillovers between coalition members may be much less effective in overcoming the strong free-rider incentives that prevail in the international climate negotiations than is commonly assumed.

Acknowledgements The authors would like to acknowledge valuable comments and suggestions from two anonymous referees. We gratefully incorporated the suggestion of a reviewer to refocus our results section on an investigation of the level and asymmetry effects of spillovers. We thank Hans-Peter Weikard for stimulating discussions. The usual disclaimer applies.

Open Access This article is distributed under the terms of the Creative Commons Attribution Noncommercial License which permits any noncommercial use, distribution, and reproduction in any medium, provided the original author(s) and source are credited.

\section{Appendix}

Table A1 Global parameters

\begin{tabular}{|c|c|c|c|c|}
\hline Symbol & Description & Value & Unit & Source \\
\hline $\bar{M}$ & Pre-industrial level of $\mathrm{CO}_{2}$ stock & 590 & $\mathrm{GtC}$ & Nordhaus (1994) \\
\hline$\delta$ & Natural annual removal rate of $\mathrm{CO}_{2}$ stock & 0.00866 & - & Nordhaus (1994) \\
\hline$\omega$ & $\begin{array}{l}\text { Airborne fraction of emissions remaining } \\
\text { in the atmosphere }\end{array}$ & 0.64 & - & Nordhaus (1994) \\
\hline$r$ & Discount rate & 0.02 & - & Assumption \\
\hline$\theta_{i}$ & Share of region $i$ in global benefits & $\begin{array}{r}\text { See Table } \\
\text { column } 3\end{array}$ & & $\begin{array}{l}\text { Own calculation based on } \\
\text { Fankhauser (1995) }\end{array}$ \\
\hline$\alpha_{i}$ & Abatement cost parameter of region $i$ & $\begin{array}{r}\text { See Table } \\
\text { column } 4\end{array}$ & & $\begin{array}{l}\text { Own calculation based on } \\
\text { Ellerman and Decaux (1998) }\end{array}$ \\
\hline$\beta_{i}$ & Abatement cost parameter of region $i$ & $\begin{array}{r}\text { See Table } \\
\text { column } 5\end{array}$ & $\mathrm{~A} 2$, & $\begin{array}{l}\text { Own calculation based on } \\
\text { Ellerman and Decaux (1998) }\end{array}$ \\
\hline$\gamma_{D}$ & $\begin{array}{l}\text { Scale parameter of damage and benefit } \\
\text { function }\end{array}$ & 0.027 & - & Tol (1997) \\
\hline
\end{tabular}


Table A2 Regional parameters in the benefit and abatement cost function

\begin{tabular}{lllll}
\hline Regions & $\begin{array}{l}\text { Emission } \\
\text { in } 2010 \\
\text { GtC (share) }\end{array}$ & $\begin{array}{l}\text { Share of global } \\
\text { benefits } \\
\theta_{i}\end{array}$ & $\begin{array}{l}\text { Parameter } \\
\text { of abatement cost } \\
\alpha_{i}\end{array}$ & $\begin{array}{l}\text { Parameter } \\
\text { of abatement cost } \\
\beta_{i}\end{array}$ \\
\hline USA & $1.763(0.238)$ & 0.226 & 0.0005 & 0.0398 \\
JPN & $0.344(0.046)$ & 0.173 & 0.0155 & 1.8160 \\
EU15 & $0.943(0.127)$ & 0.236 & 0.0024 & 0.1503 \\
OOE & $0.360(0.049)$ & 0.035 & 0.0083 & 0 \\
EET & $0.226(0.030)$ & 0.013 & 0.0079 & 0.0486 \\
FSU & $0.774(0.104)$ & 0.068 & 0.0023 & 0.0042 \\
EEX & $0.469(0.063)$ & 0.030 & 0.0032 & 0.3029 \\
CHN & $1.127(0.152)$ & 0.062 & 0.00007 & 0.0239 \\
IND & $0.344(0.046)$ & 0.050 & 0.0015 & 0.0787 \\
DAE & $0.316(0.043)$ & 0.025 & 0.0047 & 0.3774 \\
BRA & $0.122(0.016)$ & 0.015 & 0.5612 & 8.4974 \\
ROW & $0.637(0.086)$ & 0.068 & 0.0021 & 0.0805 \\
World & $7.425\left(\sum=1\right)$ & $\left(\sum \theta_{i}=1\right)$ & & \\
\hline
\end{tabular}

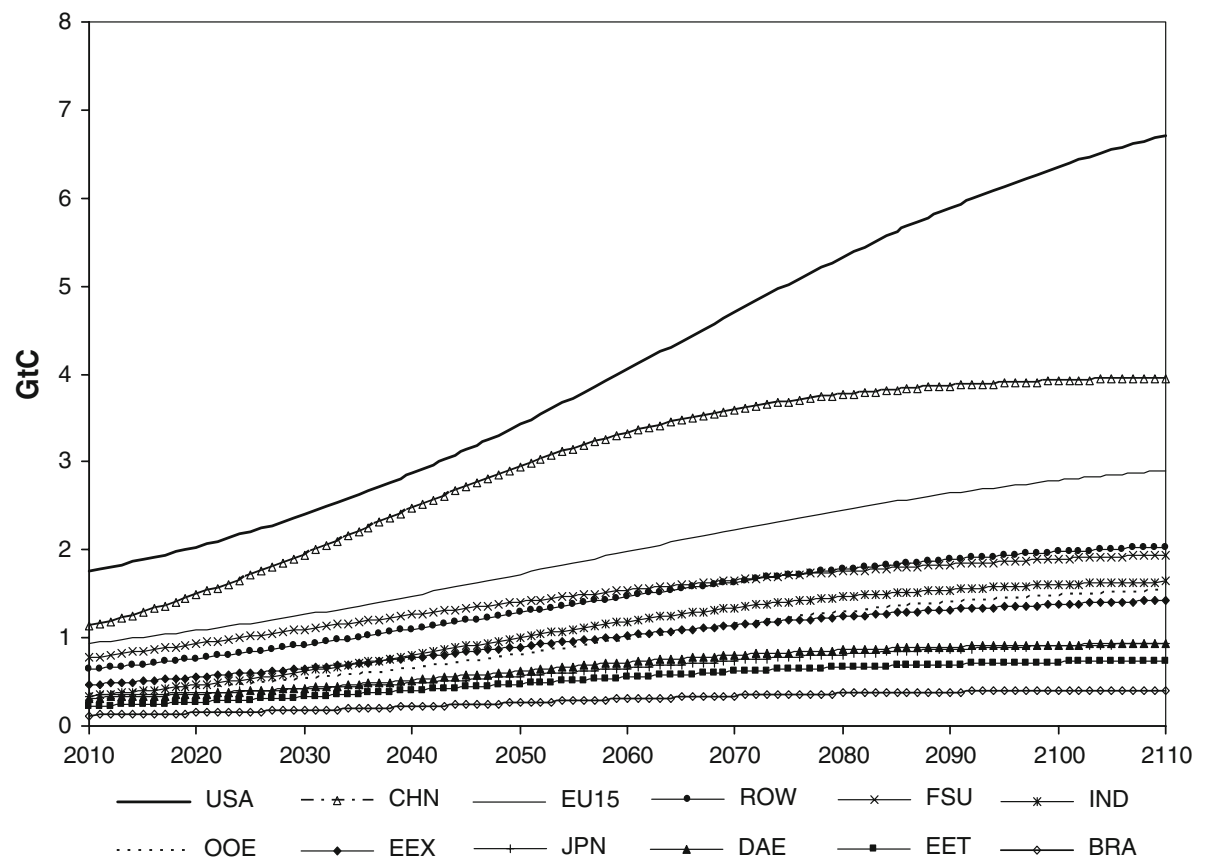

Fig. A1 Regional BAU emission paths. Source: Own calculations based on projections from the MIT-EPPA model (J. M. Reilly 2005, pers. comm.) 


\section{References}

Arrow, K. J., Chenery, H. B., Minhas, B. S., \& Solow, R. M. (1961). Capital-labor substitution and economic efficiency. The Review of Economics and Statistics, 43(3), 225-250. doi:10.2307/1927286.

Babiker, M. H., Reilly, J. M., Mayer, M., Eckaus, R. S., Sue Wing, I., \& Hyman, R. C. (2001). The MIT Emissions Prediction and Policy Analysis (EPPA) model: Revisions, sensitivities, and comparisons of results. MIT joint program on the science and policy of global change. Report No. 71. Cambridge: MIT.

Baker, E., Clarke, L., \& Shittu, E. (2008). Technical change and the marginal cost of abatement. Energy Economics (in press). doi:10.1016/j.eneco.2008.01.004.

Barrett, S. (1994). Self-enforcing international environmental agreements. Oxford Economic Papers, 46, $878-894$.

Barrett, S. (2003). Environment and statecraft: The strategy of environmental treaty-making. Oxford: Oxford University Press.

Bauman, Y., Lee, M., \& Seeley, K. (2008). Does technological innovation really reduce marginal abatement costs? Some theory, algebraic evidence, and policy implications. Environmental and Resource Economics, 40(4), 507-527. doi:10.1007/s10640-007-9167-7.

Bloch, F. (1997). Non-cooperative models of coalition formation in games with spillovers. In C. Carraro \& D. Siniscalco (Eds.), New directions in the economic theory of the environment (pp. 311-352). Cambridge: Cambridge University Press.

Bosetti, V., Carraro, C., Massetti, E., \& Tavoni, M. (2007). Optimal energy investment and R\&D strategies to stabilise greenhouse gas atmospheric concentrations, FEEM Nota di Lavoro 95.2007. Milan: Fondazione Eni Enrico Mattei.

Buchner, B., \& Carraro, C. (2005a). Modelling climate policy: Perspectives on future negotiations. Journal of Policy Modeling, 27(6), 711-732. doi:10.1016/j.jpolmod.2005.05.001.

Buchner, B., \& Carraro, C. (2005b). Economic and environmental effectiveness of a technology-based climate protocol. Climate Policy, 4(3), 229-248.

Buchner, B., \& Carraro, C. (2006). US, China and the economics of climate negotiations. International Environmental Agreements: Politics Law and Economics, 6(1), 63-89. doi:10.1007/s10784-005-1555-2.

Buonanno, P., Carraro, C., \& Galeotti, M. (2003). Endogenous induced technical change and the costs of Kyoto. Resource and Energy Economics, 25(1), 11-34. doi:10.1016/S0928-7655(02)00015-5.

Carraro, C., Eyckmans, J., \& Finus, M. (2006). Optimal transfers and participation decisions in international environmental agreements. The Review of International Organization, 1(4), 379-396. doi:10.1007/ s11558-006-0162-5.

Carraro, C., \& Siniscalco, D. (1993). Strategies for the international protection of the environment. Journal of Public Economics, 52(3), 309-328. doi:10.1016/0047-2727(93)90037-T.

Carraro, C., \& Siniscalco, D. (1994). Technical innovation and environmental protection Environmental policy reconsidered: The role of technological innovation. European Economic Review, 38(3-4), 545-554. doi:10.1016/0014-2921(94)90090-6.

Carraro, C., \& Siniscalco, D. (1997). R\&D cooperation and the stability of international environmental agreements. In C. Carraro (Ed.), International environmental negotiations: Strategic policy issues (pp. 71-96). Cheltenham: Edward Elgar.

Cesar, H., \& de Zeeuw, A. (1996). Issue linkage in global environmental problems. In A. Xepapadeas (Ed.), Economic policy for the environment and natural resources (pp. 158-173). Cheltenham: Edward Elgar.

Chander, P., \& Tulkens, H. (1995). A core-theoretic solution for the design of cooperative agreements on transfrontier pollution. International Tax and Public Finance, 2(2), 279-293. doi:10.1007/BF00877502.

Chander, P., \& Tulkens, H. (1997). The core of an economy with multilateral environmental externalities. International Journal of Game Theory, 26(3), 379-401.

Clarke, L., Weyant, J., \& Edmonds, J. (2008). On the sources of technological change: What do the models assume? Energy Economics, 30(2), 409-424. doi:10.1016/j.eneco.2006.05.023.

Coe, D., \& Helpman, E. (1995). International R\&D spillovers. European Economic Review,39(5), 859-887. doi:10.1016/0014-2921(94)00100-E.

d'Aspremont, C., Jacquemin, A., Gabszewicz, J. J., \& Weymark, J. A. (1983). On the stability of collusive price leadership. The Canadian Journal of Economics, 16(1), 17-25.

De Zeeuw, A. (2008). Dynamic effects on the stability of international environmental agreements. Journal of Environmental Economics and Management, 55(2), 163-174.

Downing, P. B., \& White, L. J. (1986). Innovation in pollution control. Journal of Environmental Economics and Management, 13(1), 18-29.

Ellerman, A. D., \& Decaux, A. (1998). Analysis of post-Kyoto $\mathrm{CO}_{2}$ emissions trading using marginal abatement curves. MIT joint program on the science and policy of global change. Report No. 40. Cambridge: MIT. 
Fankhauser, S. (1995). Valuing climate change: The economics of the greenhouse. London: Earthscan.

Finus, M., van Ierland, E., \& Dellink, R. (2006). Stability of climate coalitions in a cartel formation game. Economics of Governance, 7(3), 271-291.

Germain, M., \& van Steenberghe, V. (2003). Constraining equitable allocations of tradable $\mathrm{CO}_{2}$ emission quotas by acceptability. Environmental and Resource Economics, 26(3), 469-492.

Golombek, R., \& Hoel, M. (2005). Climate policy under technology spillovers. Environmental and Resource Economics, 31(2), 201-227.

Griliches, Z. (1992). The search for R\&D spillovers. The Scandinavian Journal of Economics, 94, S29-S47.

Grossman, G. M., \& Helpman, E. (1994). Endogenous innovation in the theory of growth. The Journal of Economic Perspectives, 8(1), 23-44.

Hirshleifer, J. (1983). From weakest-link to best-shot: The voluntary provision of public goods. Public Choice, 41(3), 371-386.

Hoel, M., \& Schneider, K. (1997). Incentives to participate in an international environmental agreement. Environmental and Resource Economics, 9(2), 153-170.

Kemfert, C. (2004). Climate coalitions and international trade: Assessment of cooperation incentives by issue linkage. Energy Policy, 32(4), 455-465.

Kemfert, C., Lise, W., \& Tol, R. S. J. (2004). Games of climate change with international trade. Environmental and Resource Economics, 28(2), 209-232.

Kennedy, C. (1962). The character of improvements and of technical progress. The Economic Journal, 72(288), 899-911.

Löschel, A. (2002). Technological change in economic models of environmental policy: A survey. Ecological Economics, 43(2-3), 105-126.

Nagashima, M., Dellink, R., \& van Ierland, E. (2006). Dynamic transfer schemes and stability of international climate coalitions. Mansholt working paper 23. Mansholt: Wageningen.

Nordhaus, W. D. (1994). Managing the global commons: The economics of climate change. Cambridge: The MIT Press.

Nordhaus, W. D., \& Yang, Z. (1996). A regional dynamic general-equilibrium model of alternative climatechange strategies. The American Economic Review, 86(4), 741-765.

Peck, S. C., \& Teisberg, T. J. (1994). Optimal carbon emissions trajectories when damages depend on the rate or level of global warming. Climatic Change, 28(3), 289-314.

Romer, P. M. (1990). Endogenous technological change. The Journal of Political Economy, 98(5), S71S102.

Sandler, T. (2006). Regional public goods and international organizations. The Review of International Organization, 1(1), 5-25.

Sandler, T., \& Tschirhart, J. (1997). Club theory: Thirty years later. Public Choice, 93(3-4), 335-355.

Tol, R. S. J. (1997). A decision-analytic treatise of the enhanced greenhouse effect. Dissertation, Vrije Universiteit, Amsterdam.

Tol, R. S. J., Lise, W., Morel, B., \& Van der Zwaan, B. (2001). Technology development and diffusion and incentives to abate greenhouse gas emissions. Research Unit Sustainability and Global Change FNU-6. Hamburg: Centre for Marine and Climate Research, Hamburg University.

Tol, R. S. J., Lise, W., \& Van der Zwaan, B. (2000). Technology diffusion and the stability of climate coalitions, FEEM Nota di Lavoro 20.2000. Milan: Fondazione Eni Enrico Mattei.

Uzawa, H. (1965). Optimum technical change in an aggregative model of economic growth. International Economic Review, 6(1), 18-31.

Weikard, H. P. (2008). Cartel stability under an optimal sharing rule. The Manchester School (forthcoming).

Weikard, H. P., Finus, M., \& Altamirano-Cabrera, J. C. (2006). The impact of surplus sharing on the stability of international climate agreements. Oxford Economic Papers, 58(2), 209-232.

Weyant, J. P., \& Olavson, T. (1999). Issues in modeling induced technological change in energy, environmental, and climate policy. Environmental Modeling and Assessment, 4(2-3), 67-85.

World Bank. (2003). World development indicators 2003 (CD-ROM edition). Washington DC: The World Bank. 